\title{
MODOS DE (NÄO) VER NOS SONETOS DE GLAUCO MATTOSO
}

\section{Susana Souto *}

Resumo: Este ensaio analisa sonetos da obra de Glauco Mattoso - poeta, tradutor, letrista, ensaísta contemporâneo -, relacionando-os a algumas referências com as quais dialogam, na medida em que se configuram, simultaneamente, como reflexão acerca da composição e da leitura do texto poético. A análise está centrada na questão do olhar, tema axial na produção desse autor.

Palavras-chave: Glauco Mattoso; poesia; leitura; soneto; olhar

[...] O poema moderno identifica a si mesmo como pensamento. Não é apenas a efetividade de um pensamento entregue no cerne da língua, é o conjunto das operações pelas quais esse pensamento se pensa.

Alain Badiou, Pequeno manual de inestética.

Soneto é o mundo inteiro em pouco espaço.

Glauco Mattoso, Geléia de rococó.

Imersos no espaço-tempo da diversidade e da rapidez, enfrentamos a impossibilidade de definições categóricas para a produção literária, em especial para a poesia. A multiplicidade - de suportes, de práticas de leitura e de autoria, bem como de programas poéticos, políticos, existenciais - é bastante visível na produção literária brasileira contemporânea, que se recusa a qualquer periodização orientada pela prevalência de traços comuns rigidamente

- Doutoranda do Programa de Pós-Graduação em Letras e Lingüística da Universidade Federal de Alagoas e professora substituta de Literatura Portuguesa da mesma universidade; professora licenciada da Universidade Católica de Brasilia. 
definidos ${ }^{\prime}$. Convivem, hoje, o projeto de experimentalismo, em sua busca de ruptura com a tradição; a poesia engajada politicamente; a poesia marginal surgida na década de 70; o vídeo-poema; a denominada "ciberpoesia coletiva". E também permanece viva uma forma fixa que surgiu na Idade Média (por volta do século XII) e mantém-se como uma das mais constantes da literatura de língua portuguesa: o soneto, o poema de catorze versos.

A produção de Glauco Mattoso, ${ }^{2}$ pseudônimo de Pedro José Ferreira da Silva, poeta paulistano nascido em 1951, constitui-se como espaço privilegiado de reflexão sobre a pluralidade de projetos, de suportes, de práticas (de autoria, leitura, edição). Poeta experimental, sonetista, tradutor, ${ }^{3}$ letrista, colunista, editor, ensaísta, esse caleidoscópio $^{4}$ de atividades chamado Glauco Mattoso está em sintonia com o contexto que Haroldo de Campos situou em "Poesia e modernidade: O Poema Pós-Utópico":

No caso da poesia brasileira, as novas gerações pósconcretas e pós-tropicalistas deixam-se caracterizar pela variedade e pela indeterminação. A mescla de estilos comparece por vezes até na obra de um único poeta. E as novas tecnologias de inscrição são acionadas em meio ao 'museu de tudo' (1997, p. 260).

1 Produção é aqui entendida em sua dimensão marcadamente materialista, em consonância com a idéia de instituição literária: "Produção implica quantidade de objetos e coletividade de produtores e consumidores. Não tem, portanto, qualquer conotação sobrenatural; é ainda mais terrena do que a palavra invenção. $\mathrm{E}$, das três palavras aqui apresentadas como possíveis [criação, invenção e produção], é a que se liga de modo mais homogêneo com a palavra texto, compreendido este como um objeto material e concreto" (PERRONE-MOISÉS, 1990, p. 101).

2 O pseudônimo remete à doença congênita que o levou à cegueira total na década de 90 do século passado: glaucoma. Glaucomatoso é o qualificativo atribuido a quem sofre de glaucoma. Segundo o autor, é também uma homenagem a Gregório de Matos.

3 Como tradutor, destaca-se seu trabalho, em parceria com Jorge Schwartz, do livro de Jorge Luis Borges Fervor de Buenos Aires, com o qual os autores ganharam o prêmio Jabuti 1999.

4 Significativamente, o pseudônimo Glauco Mattoso aparece pela primeira vez como assinatura do poema intitulado "Kaleidoscópio", de 1974. 
No entanto, é possível encontrar, a despeito dessa diversidade, um fio de continuidade, se pensarmos a elaboração poética como diálogo com outros textos, como reelaboração do que já foi produzido, já que se constitui em diálogo com uma tradição que a precede e com a qual estabelece um vínculo de resistência, contradição ou permanência (BAKHTIN, 1992; PAZ, 1994).

Este pequeno texto assume a forma do ensaio, gênero do discurso que trilha perspectivas de leitura de modo não-conclusivo e pretende traçar algumas das possibilidades de análise que os sonetos de Glauco Mattoso abrem aos seus leitores, relacionando-os as suas referências mais óbvias e discutindo em especial a questão do olhar.

\section{Soneto: permanência e renovação}

Tendo passado por vários ofícios ligados ao exercício da escrita, incluindo-se aí a sua forma musicada (atuou como letrista), Glauco Matttoso, poeta que transitou/transita por formas experimentais, provoca estranhamento ao retomar de modo sistemático, na década de 90 do século passado, uma forma fixa das mais convencionais de nossa tradição. No entanto, esse estranhamento se desfaz se observarmos a recorrência do soneto, na poesia brasileira, inclusive do século $\mathrm{XX}$, em que se encontram sonetistas como Augusto dos Anjos, Jorge de Lima, Vinicius de Moraes, e, mais recentemente, Paulo Henriques Britto, premiado, inclusive pelo Portugal Telecon, em 2004. Mesmo entre os modernistas que inicialmente assumiram uma atitude de questionamento da convenção, há um retorno ao soneto. ${ }^{5}$

Glauco Mattoso retoma o soneto e novamente inscreve-se em uma linha que começa muito antes da chegada dos portugueses a esta terra, ao publicar obras que trazem já no título a marca do seu humor e da sua inventividade, além da indicação de sua preferência por essa forma fixa: Paulicéia ilhada: sonetos tópicos (1999c), Centopéia: sonetos nojentos \& quejandos (1999a); Panacéia: sonetos colaterais (2000), Geléia de rococó: sonetos barrocos (1999b), Pegadas

5 Em especial nos livros Claro enigma e Fazendeiro do ar, de Carlos Drummond de Andrade, publicados na década de 50. 
noturnas (Dissonetos barrockistas) (2004b); Cavalo dado: sonetos cariados (2004a), entre outros (grifos meus).

Sem recusar outras veredas da poesia, Mattoso navega pelas possibilidades do soneto-passando pelo modelo italiano (petrarquiano ou petrarquista), com os 14 versos distribuídos em dois quartetos e dois tercetos; pelo modelo inglês (shakespeariano), com a distribuição em três quartetos e um dístico; bem como por modos de distribuição ainda não consagrados, nos quais joga com as possibilidades de organização espacial das palavras na folha em branco-como se apresentasse ao leitor contemporâneo uma espécie de "enciclopédia do soneto". Refletindo, em prosa, sobre o soneto, escreve:

Já que os versos são normalmente metrificados e rimados, o mais radical experimentalismo sofrido pelo soneto foi o verso branco da poesia moderna, mas outras transformações têm ocorrido, tais como a ampliação para dezessete versos pela adição dum terceiro terceto ou ESTRAMBOTE (século XVII), a recolocação dos tercetos acima dos quartetos ou entre estes (século XIX), o metro irregular e a rima aleatória. No cânone clássico o soneto tem verso decassílabo e rima abraçada nos quartetos (ABBA/ABBA) e cruzada nos tercetos (CDC/DCD). Este molde é comumente designado como "camoniano" [...] (Disponível em

$<$ http://www.glaucomattoso.sites.uol.com.br $>$ Acesso em outubro de 2004)

Mais do que pensar o soneto como uma forma que não se esgota em sua fixidez, a leitura do conjunto da produção mattosiana permite-nos observar a flexibilidade do poema de 14 versos, a sua abertura para experimentações poéticas.

Opera-se, nesse poema de 1977, um complexo processo de corte, de edição, chamado de tmese (derivado do grego tmesis), que associa a elaboração poética a técnicas de montagem cinematográfica e retoma a proposta do Concretismo (que, por sua vez, se liga aos poetas franceses do século XIX chamados "fundadores da lírica moderna", em especial Mallarmé) de uma poesia verbivocovisual, que investe na plasticidade e sonoridade do signo lingüístico, aproximando a página do livro, a partitura musical e a tela (de pintura e de cinema). 


\section{Carne Quitada}

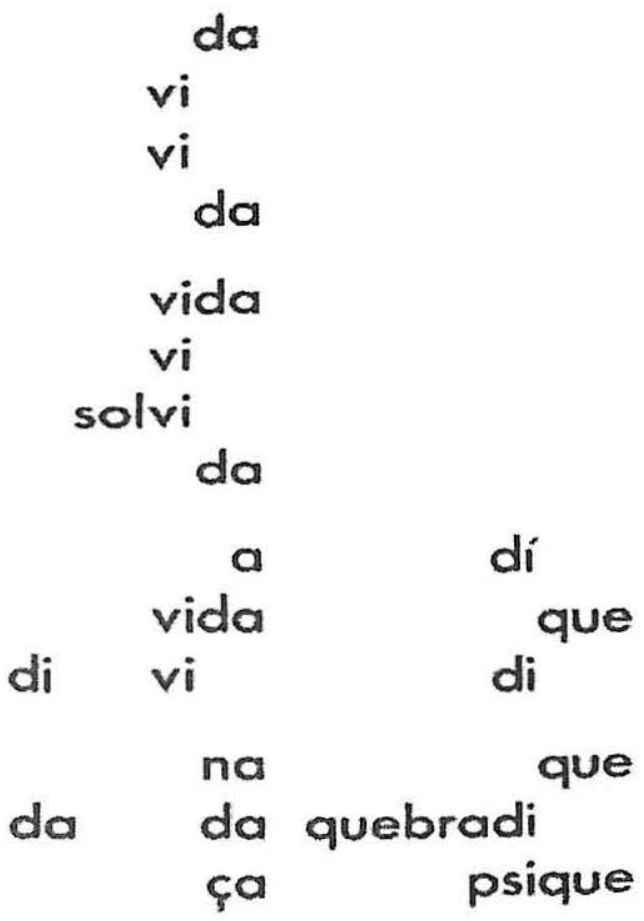

Essa referência é explicitada pelo autor de Cavalo dado: sonetos cariados (2004a), no "Soneto Peticonográfico": "Bebi do concretismo a poesia,que é líquida e se esconde atrás da pedra/ qual água no sertão: Cabral sabia" (MATTOSO, 1999b, sem indicação de página). A proximidade entre esse autor e os autores do Concretismo também se revela em uma ${ }^{6}$ das dedicatórias deste livro - Geléia de rococó:

Este livro dedico a:

Plorar: arcar com a plúvia em lágrimas alarmes.

Gonflamos amplos lenços por dolorosos

Olhos, fenestras d'água.

indicação de página)

AUGUSTO DE CAMPOS (MATTOSO, 1999b, sem

6 A outra dedicatória traz o nome de Millôr Fernandes. 
Em Geléia de rococó: sonetos barrocos (1999b), publica um apêndice intitulado "Dez considerações (desconsiderações) acerca do soneto", no qual explica como e por que é sonetista: "Não considero que o soneto tenha sido formalmente superado. [...] Dou-me ao luxo de pilheriar que o soneto vem a ser a maior invenção do Homem, depois da roda, do alfabeto latino, do algarismo arábico e da própria notação musical" (p. 123).

Depois desse elogio hiperbólico do soneto, elabora considerações de ordem formal sobre o sistema de rimas e a sua preferência pelo decassílabo, constante em sua obra: "Não considero que o verso livre, o de arte menor, ou mesmo o alexandrino, seja mais adequado ao soneto que o decassílabo, pela simples razão de que o deca é irredutível ao hemistíquio, isto é, indivisível à metade, conquanto comporte duas cesuras, que o articulam em três pés" (1999b, p. 124).

A incorporação do crítico ao seu projeto de escritura/leitura, $\mathrm{em} /$ de suas obras, aparece em sua produção de diversas formas (em seus livros - apresentações, advertências, posfácios - e divulgados em seu site oficial e em outros sites que tratam de poesia). Em um deles, temos algo incomum em um livro de poemas: uma nota de rodapé no soneto 2.13, do livro Centopéia: sonetos nojentos e quejandos (1999), sobre o último verso ("lamber a sola de quem tem visão"), na qual lêse: "Este verso, excepcionalmente sáfico, pode igualar-se aos demais no acento heróico, se adotada a variante: lamber-te a sola a ti, que tens visão".

Os metapoemas e os textos em prosa de Glauco Mattoso compõem uma espécie de projeto de leitura, que guia o leitor na tradição do soneto, na tradição de língua portuguesa e em outras, destacando elementos formais de diversas ordens.

\section{Cegueira, pseudônimo e poesia}

No Ocidente, a visão é um sentido considerado central na percepção do mundo e do corpo. A metáfora de olhos como "janelas da alma" foi largamente difundida. Mesmo Platão, avesso a uma percepção de mundo que tinha como veículo principal os sentidos, concedeu ao olhar um lugar especial, por este prescindir do contado direto com aquilo que era olhado, e, no diálogo Fedro, diz: "a vista é o mais sutil dos órgãos do corpo" (1975, 250-d). 
Segundo Gerd A. Borheim (1999), a importância do olhar no mundo grego é indicada pelas modalidades desse verbo em grego, vinculando ver e conhecer. Ver liga-se a contemplar e também à teoria, indicando algo que pode assumir tanto em uma dimensão exterior, quanto interior, mas que não se esgota na simples observação do mundo empírico. Na celebrada tragédia de Sófocles, significativamente, Édipo Rei fura os próprios olhos, quando confrontado com a verdade de que era ele o responsável pelos males que assolavam a cidade de Tebas. $\mathrm{Na}$ tradição literária brasileira, provavelmente a mais célebre imagem de olhos, que é, simultaneamente, metafórica e metonímica, está em Dom Casmurro, reiterada no título de dois capítulos do romance machadiano, tema de diversos textos de sua fortuna crítica.

Nas poéticas clássicas, a relação entre ver e escrever é afirmada em especial pela célebre fórmula de Horácio, em seu Arte poética ou Epistolae ad pisones, que propõe aproximações entre a poesia e as artes visuais: "Ut pictura poesis; erit quae, si propius stes, te capiat magis, et quaedam, si longuis abstes; haec amat obscurum, uolet haec sub luce uideri, udicis argutum quae nom formidat acumen". A poesia era, assim, uma pintura feita com palavras.

Nos poemas de Glauco Mattoso, a tematização do olhar se dá pelo seu avesso: a cegueira. Um modo de (não) ver o mundo e a poesia, o poeta e o seu tempo. O poeta usa a impossibilidade de ver para nomear-se, escolhendo como máscara uma limitação.

O que poderia ter sido causa do silêncio, do distanciamento do autor em relação à produção poética, é transformado naquilo que o impulsiona à escrita. A cegueira, ainda, orienta a divisão de sua obra em duas fases: a visual e a cega (CAMPOS, 2004, p. 203). ${ }^{7}$ Tendo começado com experimentações no campo da poesia visual, Glauco Mattoso migrou para o soneto, movido pela impossibilidade de revisar os seus poemas com o olhar, podendo apenas ouvi-los.

7 Em texto publicado como posfácio em Pegadas noturnas (Dissonetos barrockistas) e disponível no site oficial de Glauco Mattoso, <http://glaucomattoso.sites.uol.com.br>). 
Em seus poemas, a cegueira é, portanto, axial: seja para orientar a escolha do nome com o qual assina seus livros, seja para reivindicar pertencimento a um grupo de autores, seja como tema de poemas. A escolha do soneto como forma para os seus poemas é também associada pelo autor à perda da visão. Com a perda desse sentido, outros foram substituindo-o como possibilidade de percepção do mundo, da língua. Assim, o soneto instaura-se como saída para a produção poética pela sua exatidão em termos de sonoridade, pelo seu caráter melopaico demarcado e definido, como lemos na apresentação, intitulada "Advertência", de Centopéia: sonetos nojentos e quejandos (1999):

Creio ter encontrado no soneto a fórmula mais disciplinar, mnemônica e laconicamente falando, para canalizar minha angústia sem abrir mão do pé, um fetiche arraigado, que agora se eleva à categoria de célula temática, em torno da qual cada poema funciona como variação orquestral.

Não só o soneto, mas, como ainda nesse texto, especifica o autor, o soneto em sua versão camoniana: "No tocante ao rigor da forma, adotei o modelo camoniano, por entender que o decassílabo heróico é o que empresta maior cadência a um gênero supostamente decadente".

O poeta se autonomeia, recusa o nome imposto pelo pai, pela Lei, e substitui essa nomeação primeira pela criação de um nome outro, reinventando-se em sua poesia. Glauco Mattoso, porém, brinca com essa escolha, ao propor outras interpretações para o nome escolhido, em "Soneto glauquiano" (Paulisséia ilhada: sonetos tópicos, soneto $2.188,1999)$ :

O próprio no sentido figurado:

Mattoso quer dizer interiorano

ou louco, no entender dum italiano;

e Glauco quer dizer esverdeado.

$\mathrm{Na}$ lenda tem assento reservado:

foi célebre entre os deuses do oceano.

Ao dom da profecia era profano, mas por Apolo foi presenteado. 
Foi Circe, a feiticeira enciumada, quem não deixou que Glauco amasse Cila, a linda ninfa, em monstro transformada.

Mas este Glauco é cego, e não vacila na triste condição que lhe foi dada de, mesmo monstruosa, preferi-la.

Nesse soneto, a apresentação do nome confunde-se com a apresentação de uma concepção poética. O jogo que se institui entre as duas palavras que o nomeiam, reforçando a referência ao campo mato e verde -, parece, em uma leitura apressada, associar-se a uma poesia em que predomina o locus amoenus dos árcades, associação reforçada pela posterior citação da mitologia greco-latina para explicar/justificar essa escolha. Nos dois quartetos finais do soneto, essa leitura, como apego à convenção, é desautorizada, pois processase a inversão paródica, anunciada pelo uso da conjunção adversativa mas, que estabelece uma relação de oposição e tensão entre o que foi anteriormente dito e o que será em seguida enunciado. Lê-se, então, a partir da adversativa, a escolha anticonvencional do poeta, que inverte o final do mitema, em sua forma original, na qual Cila é afastada de Glauco pela sua fealdade; na leitura mattosiana, ao contrário, a monstruosidade aproxima-os:

Mas este Glauco é cego, e não vacila na triste condição que the foi dada de, mesmo monstruosa, preferi-la.

A cegueira é, assim, apresentada como um modo diferente de ver; a triste condição é, paradoxalmente, a condição de possibilidade para a realização do pacto amoroso, para a derrota de Circe, não do amor dos personagens mitológicos, de triste transforma-se, inversa e parodicamente, em alegre. A cegueira transfigura-se em um modo de ver, e, simultaneamente, transfigura o modo de ver/ler também o conjunto de narrativas que o cânone nos oferece.

Em outro poema que tem como núcleo a cegueira, lemos: “O cego viu que o rei se achava nu,/ enquanto alguém que tem dever de ver/ coloca-se a serviço do poder,/levando, sem gemido, o pau no cu" (idem, soneto 2.189). Por meio do recurso dialógico ou intertextual nesse caso, com a conhecida narrativa infantil - ocorre uma 
associação entre cegueira e infância, o cego corresponde, em uma cadeia paradigmática, ao menino que diz/vê que "O rei está nu". Mais uma vez, eleva-se a cegueira a uma concepção privilegiada de ver, correlata à da criança, ainda não formatada pelas convenções sociais.

Como já destacou Alves (2004), a cegueira liga-se também à memória e à elaboração poética, em diversos poemas de Glauco Mattoso: "Cegueira é um bom termômetro do grau/ da férrea disciplina da memória/ perdida na deriva duma nau" (Paulisséia ilhada: sonetos tópicos, soneto 2.198).

É ainda a cegueira (total ou parcial, metafórica ou verdadeira) que o filia a uma galeria de autores à qual reivindica pertencimento e na qual inclui, de modo não-hierárquico, Camões, Homero, Borges, Cego Aderaldo:

\section{SONETO 244 PRODIGIOSO}

Quem sabe o maior mérito de Homero

foi ter feito o que fez sem ter visão.

Se Borges, Aderaldo ou Lampião

fizeram, vou fazer também, espero.

Zarolho ou cego, não quero ser mero

passivo espectador da ocasião.

Verei o que videntes não verão;

Se sábios não souberam, eu supero.

Beethoven era surdo, e foi maior.

O grande escultor nosso era sem mãos.

Perder não é dos males o menor.

Abaixo estou de todos meus irmãos.

Que o mais pecaminoso sou pior.

Meu trunfo é só não ter dois olhos sãos.

(Geléia de rococó, 1999)

A rede de referências não se restringe à literatura. A falta aproxima Beethoven e Aleijadinho, como prodígios que superam dificuldades aparentemente intranponíveis: compor sem ouvir, esculpir quase sem as mãos. No soneto transcrito abaixo, há uma associação entre Mattoso e Camões pela perda da visão. Referência 
constante em sua obra, o poeta português atua como um modelo, de quem se diz neto bastardo, mas, ainda assim, herdeiro.

\section{SONETO EPÍGONO [131]}

Indagam-me em qual ídolo me espelho, se em Sade ou se em Masoch, Artaud, Rimbaud, Jarry, Villon, ou certo autor pornô com fama de trepar feito coelho.

Pergunta embaraçosa! Estou vermelho, temendo parecer muito retrô...

Mas não venero um Pai, venero o Avô, perante o qual não passo dum fedelho.

Me orgulho se chegar-lhe a ser pimpolho; Já basto-me, porém, sendo bastardo, e ao limbo dos herdeiros me recolho.

Camões é meu modelo como bardo, até porque também perdeu seu olho. Perdi dois: só lhe sou maior no fardo...

(Paulisséia ilhada, 1999)

Leitor e autor confundem-se nos versos produzidos por Mattoso, poeta que deixa marcas explícitas das suas leituras em seus poemas. Nessa incorporação dialógica, ou antropofágica, vai sendo composto o seu paideuma. Paulo Henriques Britto abordou essa questão, em um texto intitulado "Memória e poesia" (2000), no qual discute a substituição, na poesia contemporânea, da memória do vivido por uma memória do lido. Na produção mattosiana, a memória do lido convive, no poema, com a memória do vivido/recriado. ${ }^{8}$ As

8 Chega a filiar-se à galeria de autores que parodiaram o mais ufanista dos poemas românticos, "A canção do exilio", de Gonçalves Dias, em uma seção do Jornal DOBRABIL (2001), intitulada ironicamente "Cor local":

"Minha terra tem mais terra

minha fome tem mais cores

minha cor que menos berra

é a que sente minhas dores" 
leituras formam uma teia discursiva, na qual se delineia um quadro de referências que nos falam da permanência da poesia em um mundo que parece feito contra ela.

\section{Alguma conclusão}

Mattoso experimentalista, Mattoso sonetista. Não há possibilidade de separação dicotômica, como se o segundo correspondesse ao tradicional e o primeiro, ao inovador. Mattoso experimenta as possibilidades do soneto, da tradição. A leitura da sua obra leva-nos à questão da tradição versus inovação, na medida em que cada texto é apenas uma fala, ou melhor, uma resposta, como postula Bakhtin, em uma longa cadeia de enunciação, na qual não há originalidade absoluta, na medida em que o autor de qualquer enunciado.

[...] não é o primeiro locutor, que rompe pela primeira vez o eterno silêncio de um mundo mudo, e pressupõe não só a existência do sistema da língua que utiliza, mas também a existência de enunciados anteriores emanantes dele mesmo ou do outro - aos quais seu próprio enunciado está vinculado por algum tipo de relação (fundamenta-se neles, polemiza com eles), pura e simplesmente ele já os supõe conhecidos do ouvinte (BAKHTIN, 1992, p. 291).

A leitura é, assim, uma prática que

[...] deriva de formas transindividuais: as associações engendradas pela letra do texto (mas onde está essa letra?) nunca são, façamos o que fizermos, anárquicas; são sempre tiradas (colhidas e inseridas) de certos códigos, de certas línguas, de certas listas de estereótipos. A leitura mais subjetiva que se possa imaginar nunca é senão um jogo conduzido a partir de certas regras (BARTHES, 1984, p. 28).

Essas regras serão discutidas por Mattoso, tanto em seus textos ensaísticos, quanto em seus textos literários.

Como projeto de leitura, uma vez que as práticas de escrita e leitura são correlatas e estão intimamente associadas, acompanhamos 
o trânsito do poema mattosiano pela poesia brasileira e também por outras tradições, trânsito que tem, como fio de continuidade, o poema de 14 versos, no qual, muitas vezes, a cegueira é nosso guia.

Remetendo o leitor dos seus textos para os textos de seus autores preferidos, reivindicando a leitura e, assim, a permanência desses autores, pois:

Tanto a ruptura como a irrupção são relativas: cada mudança confirma a tradição e a continua, cada inovação se alimenta das invenções do passado, cada ruptura é uma reiteração e uma homenagem às obras dos nossos avós (PAZ, 1993, p. 120).

Mattoso propõe um programa de leitura, uma carta de navegação por esse conjunto muitas vezes navegado, complexo e imenso, chamado literatura.

\section{Referências}

De Glauco Mattoso

MATTOSO, Glauco. Cavalo dado: sonetos cariados. São Paulo: 100 (Sem) Leitores, 2004a.

Centopéia: sonetos nojentos e quejandos. São Paulo: Edições Ciência do Acidente, 1999a.

Contos familiares: sonetos requentados. São Paulo: 100 (Sem) Leitores, 2003.

Geléia de rococó: sonetos barrocos. São Paulo: Edições Ciência do Acidente, 1999b.

JORNAL DOBRABIL: 1977/1981. São Paulo: Iluminuras, 2001.

Paulisséia ilhada: sonetos tropicais. São Paulo: Edições Ciência do Acidente, 1999c.

Panacéia: sonetos colaterais. São Paulo: Nankin Editorial, 2000. (Coleção Janelas do Caos).

Pegadas noturnas (Dissonetos barrockistas). Rio de Janeiro: Lamparina, 2004b.

Poesia digesta (1974-2004). São Paulo: Landy Editora, 2004c. 
O soneto no Brasil. Disponível em http://glaucomattoso.sites.uol.com.br http://formattoso.sites.uol.com.br. Acesso: outubro de 2004; novembro de 2005.

De outros autores

ALVES, Franklin. Esse elogio da sombra: poesia e cegueira em Glauco Mattoso. In: MATTOSO, Glauco. Pegadas noturnas (Dissonetos barrockistas). Rio de Janeiro: Lamparina, 2004.

BADIOU, Alain. Pequeno manual de inestética. Trad. Marina Appezeller. São Paulo: Estação Liberdade, 2002.

BAKHTIN, M. Estética da criação verbal. Trad. Maria Ermantina Galvão Gomes Pereira. São Paulo: Martins Fontes, 1992.

BARTHES, Roland. O rumor da lingua. Trad. de António Gonçalves. Lisboa: Edições 70, 1987.

BARTHES, Roland \& COMPAGNON, Antoine. Leitura. In: Enciclopédia Einaudi. Vol. 11 Oral/Escrito Argumentação. Trad. Teresa Coelho. Lisboa: Imprensa Nacional-Casa da moeda, 1987.

BORHEIM, Gerd A. As metamorfoses do olhar. In NOVAIS, Adauto (org.). O olhar. São Paulo: Companhia das Letras, 1999.

BRITO, Paulo Henriques. Memória e poesia. In: PEDROSA, Célia. Mais poesia hoje. Rio de Janeiro: 7 Letras, 2000.

CAMPOS, Haroldo. O arco-íris branco. Rio de Janeiro: Imago, 1997. CAMPOS, Pedro Ulisses. O poeta passado a sujo. In: MATTOSO, Glauco. Poesia digesta (1974-2004). São Paulo: Landy Editora, 2004.

PAZ, Octavio. La casa de la presencia: poesia e historia. Obras completas. Ciudad de Mexico: Círculo de Letores/Fondo de Cultura Económica, 1994.

PAZ, Octavio. A outra voz. Trad. Waldir Dupont. São Paulo: Siciliano, 1993.

PERRONE-MOISÉS, Leyla. Flores da escrivaninha: ensaios. São Paulo: Cia. das Letras, 1990.

PLATÃo. Fedro. Diálogos. Vol. IV. Tradução de Carlos Alberto Nunes. Belém: Editora da Universidade Federal do Pará, 1975. 